\title{
Factors Stimulating Treatment in a Certified Breast or Prostate Cancer Center
}

\author{
Raja Schirrmacher \\ Cancer Registry of Rhineland-Palatine \\ Ruben Hamann \\ Cancer Registry of Rhineland-Palatine \\ Christina Justenhoven ( $\square$ justenhoven@krebsregister-rlp.de) \\ Cancer Registry of Rhineland-Palatine https://orcid.org/0000-0002-4056-0921
}

\section{Research Article}

Keywords: Breast cancer, Prostate cancer, DKG-certified center, Decision factors

Posted Date: January 27th, 2022

DOI: https://doi.org/10.21203/rs.3.rs-1020930/v1

License: (c) (i) This work is licensed under a Creative Commons Attribution 4.0 International License. Read Full License 


\section{Abstract}

The German Cancer Society (DKG) offers certification of oncological centres since 2003. Meanwhile more than 260 and more than 120 certified centres for breast and prostate cancer, respectively, exist in Germany. Aim of the herein performed investigation was the identification of factors that stimulate treatment of patients with breast or prostate cancer in a certified centre. This study was based on information available in the database of the Cancer Registry of Rhineland-Palatinate, Germany. The impact of age, region of residence, tumor status, grading and presence of metastasis on patient's decision with respect to a certain medical facility was analyzed by adjusted logistic regression. This investigation included data of 13,020 breast cancer and 10,904 prostate cancer patients diagnosed in the years 2016 to 2020 . Overall, $59 \%$ and $28 \%$ of breast and prostate cancer patients, respectively, were treated in a DKG-certified centre. The analyses showed that residence in an urban region was associated with treatment in a certified centre (breast: OR $0.42,95 \% \mathrm{Cl}(0.37-0.48)$; prostate: OR $0.4695 \% \mathrm{Cl}(0.40-0.53)$ ). In addition, older breast cancer patients were more often treated in hospitals without certificate (OR 1.13, 95\% Cl (1.04-1.24). Prostate cancer showed no association with age but early tumor stage ( $\mathrm{T} 1$ ) were more often treated in hospitals without certificate (OR $1.23,95 \% \mathrm{Cl}(1.03-1.46)$. In contrast, patients with more advanced tumors, T2 and T3, were likely to be reported by DKG-certified centres (OR $0.58,95 \% \mathrm{Cl}(0.41-0.81)$ and OR 0.67 , $95 \% \mathrm{Cl}(0.47-0.96)$, respectively). Most breast and more than a quarter of prostate cancer patients were treated in DKG-certified centres. The region of residence seemed to affect the decision for a certain facility for all patients. Whereas age at diagnosis and tumor status played a role for breast and prostate cancer patients, respectively.

\section{Introduction}

Cancer is a leading cause of death worldwide and there is substantial potential to reduce the burden of cancer mortality by appropriate treatment and care of patients [1]. Meanwhile numerous campaigns have been initiated and several certification programs have been developed to ensure that state of the art of care is translated into praxis. In Germany the nationwide Cancer Care Certification Program was implemented by the German Cancer Society (Deutsche Krebsgesellschaft, DKG) in 2003. The aim of this program is the improvement of quality of cancer care with the intention to put recommendations of clinical guidelines into praxis and provoke the establishment of multidisciplinary networks. Meanwhile more than 1,700 DKG-certified centers exist in Germany [2], although, participation in this program is voluntary [3, 4] and certification represents a time consuming and expensive process including yearly on-site audits and full re-evaluation-audits every three years $[5,6]$. One crucial evaluation criterion refers to the number of cancer cases treated annually [4]. Accordingly, it is of certain interest to understand which factors encourage patients to visit a certified center. The dataset of the Cancer Registry of Rhineland-Palatine represents a reliable basis for such investigation, due to its comprehensive real-world setting [7]. The herein conducted study comprised parameters that might impact the decision of breast and prostate cancer patients for or against treatment in a certified center. These entities were selected because they represent two of the most commonly occurring cancers worldwide [8]. Our analyses were focused on age at diagnosis, region of residence, tumor size, grading and metastatic status.

Age is a crucial factor with respect to adaption of treatment modalities $[9,10]$ and therefore might also impact decision for a certain medical facility. In addition, patients with age-related reduced mobility might favor treatment in the nearest facility irrespective of the certification status.

Choice of a certain hospital might also be affected by the region of residence of a patient. Urban dwellers have access to variety of medical facilities including certified centers in short distance [11]. Travel to reach a certified center may be costly and burdensome for inhabitants of rural regions [12], therefore, they might prefer hospitals in close environment.

Tumor status, grading and metastatic status represent important prognostic factors which also impact the selection of the appropriate therapy regimen $[10,9]$. It is of interest to understand if patients with poor prognosis might prefer medical care in a certified center.

Each of these parameters holds the potential to affect decision for treatment in a facility with or without DKG-certificate, beyond that multifactor interaction needs to be considered. For instance, elderly women with breast cancer present more frequently with advanced disease [13]. Thus, adjusted logistic regression was performed to take potential interaction between all analyzed parameters into account. To the best of our knowledge this is the first study which analyzed factors that might stimulate decision of patients for treatment in a DKG-certified center in Germany.

\section{Material And Methods}

This study was based on information available in the database of the Cancer Registry of Rhineland-Palatinate, Germany. Cancer registration in the German federal state Rhineland-Palatinate originally started on the level of epidemiological data, covering a population of approximately 4 million inhabitants. For this aim an epidemiological cancer registry was founded in 1997 [7]. Until end of 2015 basic information on incidence, prevalence, mortality and survival of cancer patients were collected. In 2016 epidemiological cancer registration was transferred to the newly founded clinical cancer registry. Main focus of the new facility was the collection of comprehensive data regarding diagnosis, histo-pathological characteristics of tumors, treatment and follow-up of cancer patients, resident and/or treated in Rhineland-Palatinate. Since datasets need to be 
comparable among cancer registries in Germany, survey of data was standardized by introducing the nationwide uniform oncological dataset [14]. As of yet, personal and medical information as well as follow-up data of more than 100,000 patients are available in the dataset of the Cancer Registry of Rhineland-Palatinate. Moreover, each day more than 900 new reports are included into the database.

Our investigation included breast and prostate cancer cases diagnosed in the years 2016 to 2020 . The impact of age, region of residence, tumor status, grading and presence of metastasis on patient's decision with respect to a certain medical facility was analyzed by adjusted logistic regression.

Classification of treatment in a DKG-certified center or a non-certified medical facility was based on the source of the diagnostic report. In case diagnostic reports where inaccessible patients were classified with respect to the source of the surgery report. Information on the certification status of each facility was gathered from the webpage OncoMap (status February 2021) [2].

Age at diagnosis was calculated on the basis of information on the date of birth and date of diagnosis. Three age classes were defined for each tumor entity with respect to the respective age-specific incidence rate [15]. Accordingly, breast cancer patients were divided into the following classes: age at diagnosis $<50,50-70$ and older than 70 years of age. Age classes of prostate cancer patients were: age at diagnosis $<60,60-70$ and older than 70 years of age. For both entities the second group included the mean age at diagnosis, therefore, this class was used as reference in statistical analyses.

The investigation was focused on patients living in Rhineland-Palatinate. Assignment to a certain region of residence was based on postal code of home address at time of diagnosis. Information on number of inhabitants in the respective area was retrieved from the Federal Statistical Office [16]. Three groups were formed: patients living in rural regions with $\leq 5,000$ inhabitants, small and medium-sized towns with 5,000 to 50,000 inhabitants as well as medium-sized and large towns with $>50,000$ inhabitants. The second group was used as reference in statistical analyses.

Analyses with respect to tumor status $(T)$ were based on information on tumor size and extent [17]. Classification for breast tumors was: $T 1=$ $\leq 2 \mathrm{~cm}, \mathrm{~T} 2=>2 \mathrm{~cm} \leq 5 \mathrm{~cm}, \mathrm{~T} 3=>5 \mathrm{~cm}, \mathrm{~T} 4=$ involvement of skin and chest wall. Classification for prostate tumors was: T1 = clinically inapparent, not palpable, T2 = confined within prostate, T3 = extends through the prostatic capsule, T4 = fixed or invades adjacent structure. For both entities the number of cases which were treated in certified centers and non-certified facilities was similar in the class of T4 tumors (Tables 1 and 2), therefore, this group was used as reference in statistical analyses. 
Table 1

Comparison of breast cancer patients treated in certified centers vs. non-certified facilities

\begin{tabular}{|c|c|c|c|c|}
\hline \multirow{3}{*}{ Variables } & \multicolumn{4}{|c|}{ Breast cancer patients $(N=13,020)$} \\
\hline & DKG certified center & Non-certified center & Adjusted OR (95\% Cl) & P-value \\
\hline & $N(\%)$ & $N(\%)$ & & \\
\hline \multicolumn{5}{|c|}{ Age at diagnosis } \\
\hline$<50$ & $1,033(13.4)$ & $738(13.9)$ & $1.07(0.95-1,21)$ & 0.276 \\
\hline $50-70$ & $3,935(51.0)$ & $2,481(46.8)$ & Reference & \\
\hline$>70$ & $2,748(35.6)$ & 2,085 (39.3) & $1.13(1.04-1.24)$ & 0.006 \\
\hline \multicolumn{5}{|c|}{ Region of residence (inhabitants) } \\
\hline$\leq 5,000$ & $3,252(42.1)$ & $2,596(48.9)$ & $0.99(0.91-1.09)$ & 0.880 \\
\hline $5,000-50,000$ & $2,214(28.7)$ & $1,864(35.2)$ & Reference & \\
\hline$>50,000$ & $2,250(29.2)$ & $844(15.9)$ & $0.42(0.37-0.47)$ & $<0.001$ \\
\hline \multicolumn{5}{|l|}{ Tumor size } \\
\hline T1 & $3,843(50.5)$ & $2,028(51.0)$ & $0.88(0.75-1.04)$ & 0.144 \\
\hline $\mathrm{T} 2$ & $2,850(37.5)$ & $1,450(36.4)$ & $0.89(0.75-1.05)$ & 0.163 \\
\hline T3 & $432(5.7)$ & $223(5.6)$ & $0.87(0.69-1.10)$ & 0.248 \\
\hline T4 & $483(6.3)$ & $279(7.0)$ & Reference & \\
\hline \multicolumn{5}{|l|}{ Grading } \\
\hline low & $5,330(70.8)$ & 3,346 (71.3) & Reference & \\
\hline high & $2,195(29.2)$ & $1,344(28.7)$ & $0.97(0.89-1.06)$ & 0.537 \\
\hline \multicolumn{5}{|c|}{ Metastatic status } \\
\hline MO & $7,004(92.0)$ & 3,387 (89.0) & Reference & \\
\hline M1 & $605(8.0)$ & $420(11.0)$ & $1.05(0.90-1.21)$ & 0.558 \\
\hline
\end{tabular}


Table 2

Comparison of prostate cancer patients treated in certified centers vs. non-certified facilities

\begin{tabular}{|c|c|c|c|c|}
\hline \multirow{3}{*}{ Variables } & \multicolumn{4}{|c|}{ Prostate cancer patients $(N=10,904)$} \\
\hline & DKG certified center & Non-certified center & Adjusted OR (95\% Cl) & $P$-value \\
\hline & $N(\%)$ & $N(\%)$ & & \\
\hline \multicolumn{5}{|c|}{ Age at diagnosis } \\
\hline$<60$ & $337(11.0)$ & $765(9.8)$ & $1.01(0.86-1.20)$ & 0.877 \\
\hline $60-70$ & $1,055(34.5)$ & 2,437 (31.1) & Reference & \\
\hline$>70$ & $1,670(54.5)$ & $4,640(59.1)$ & $0.98(0.88-1.09)$ & 0.719 \\
\hline \multicolumn{5}{|c|}{ Region of residence (inhabitants) } \\
\hline$\leq 5,000$ & $1,259(41.1)$ & $3,862(49.3)$ & $1.13(1.01-1.27)$ & 0.046 \\
\hline $5,000-50,000$ & $857(28.0)$ & $2,471(31.5)$ & Reference & \\
\hline$>50,000$ & $946(30.9)$ & $1,509(19.2)$ & $0.46(0.40-0.53)$ & $<0.001$ \\
\hline \multicolumn{5}{|l|}{ Tumor size } \\
\hline T1 & $920(30.7)$ & $2,994(50.0)$ & $1.23(1.03-1.46)$ & 0.022 \\
\hline T2 & $1,426(47.5)$ & $1,919(32.1)$ & $0.58(0.41-0.81)$ & 0.001 \\
\hline T3 & 598 (19.9) & $936(15.6)$ & $0.67(0.47-0.96)$ & 0.027 \\
\hline T4 & $57(1.9)$ & $136(2.3)$ & Reference & \\
\hline \multicolumn{5}{|l|}{ Grading } \\
\hline low & $1,610(56.2)$ & 3,939 (58.9) & Reference & \\
\hline high & $1,257(43.8)$ & $2,753(41.1)$ & $0.96(0.87-1.06)$ & 0.427 \\
\hline \multicolumn{5}{|c|}{ Metastatic status } \\
\hline M0 & 2,708 (90.6) & 3,541 (89.0) & Reference & \\
\hline M1 & $280(9.4)$ & $436(11.0)$ & $0.92(0.77-1.11)$ & 0.382 \\
\hline
\end{tabular}

With respect to histological grading tumors were classified in low-grade and high-grade tumors. The class "low" included tumors designated G1, G2, G1/2 and low, the class "high" included G3, G4, G3/4 and high. Tumors with intermediate grade or classified as G2/3 did not fit to any of these classes and were therefore excluded from the analysis. The subgroup of well differentiated tumors "low" was used as reference in statistical analyses.

Analyses focused on metastatic status were based on information on prevalence of distant metastases [17]. Absence of clinical detectable metastases was designated as M0. In contrast, M1 indicates presence of metastases. The subgroup of patients with metastatic status M0 was used as reference in statistical analyses.

For each of these factors potential impact on the choice of a certified or non-certified medical facility was analyzed. Adjusted logistic regression was performed to take potential interaction between all analyzed parameters into account. Odds Ratios (ORs) with $95 \%$ confidence interval (CI) and $P$-values were calculated. ORs $<1$ indicated a greater proportion of patients treated in DKG-certified centers. In contrast, ORs $>1$ indicated a greater proportion of patients reported by medical facilities without certificate. The technologies R[18] and SPSS[19] were used for preparation of datasets and statistical analysis.

\section{Results}

13,020 breast cancer and 10,904 prostate cancer patients were included in statistical analyses. It was based on epidemiological and clinical information which was reported to the Cancer Registry of Rhineland-Palatinate and had passed internal quality control. Our study showed that $59 \%$ of breast cancer patients (Table 1 ) and $28 \%$ prostate cancer patients (Table 2 ) were treated in a DKG-certified center. Subgroup analysis by adjusted logistic regression revealed that breast cancer patients living in urban regions were more often treated in a certified center (OR 0.42 , 
$95 \% \mathrm{Cl}(0.37-0.48)$; Table 1). In addition, an association between $>70$ years of age and treatment in medical facilities without certificate was observed (OR 1.13, 95\% Cl (1.04-1.24); Table 1).

With respect to the region of residence also prostate cancer patients living in urban regions were more often treated in certified centers (OR 0.46 $95 \% \mathrm{Cl}(0.40-0.53)$; Table 2). Moreover, statistical analysis revealed an association between small prostate tumors (T1) and treatment in medical facilities without certificate (OR 1.23, 95\% Cl (1.03-1.46); Table 2). In contrast, patients with more advanced tumors, T2 and T3, were likely to be reported by DKG-certified centers (OR $0.58,95 \% \mathrm{Cl}(0.41-0.81)$ and $\mathrm{OR} 0.67,95 \% \mathrm{Cl}(0.47-0.96)$, respectively).

For none of the other variables statistically significant effects were observed.

\section{Discussion}

In 2003 the German-wide Cancer Care Certification Program was initiated by the DKG and meanwhile more than 262 and more than 120 certified centers for breast and prostate cancer, respectively, exist [2]. Aim of this study was to identify factors may affecting the decision of a breast or prostate cancer patient for or against treatment in a DKG-certified center. The analyses of the real-world dataset provided by the Cancer Registry of Rhineland-Palatinate revealed that more than twice as many breast cancer patients than prostate cancer patients were treated in a certified center in the period 2016 to 2020 . However, three as many certified breast cancer centers than prostate cancer centers existed in RhinelandPalatinate [2].

Beyond, accessibility to certified centers even adherence to guideline-driven treatment may impact visiting rates to certain facilities. In particular, all stages of breast tumors are usually resected by surgery [9] making hospitalization inevitable. In contrast, guidelines recommend active surveillance for early staged prostate tumors [10], a procedure usually performed in an ambulatory setting. These differences in treatment modalities were reflected by the results of statistical analyses regarding tumor status No association between dimensions of breast tumors and certification status of medical facilities was observed. In contrast, early prostate tumors (T1) were more frequently reported to the Cancer Registry by non-certified facilities.

However, concordant effects were observed for both entities with respect to region of residence of patients. Urban dwellers seemed to prefer certified centers, an effect potentially promoted by the solely urban location of these facilities [2]. Accordingly, the probability to choose a certified center either deliberately or by chance was much higher for patients living in large towns than for those residing in rural regions. For the latter also travel burdens might impact attention to a special healthcare facility [12]. These aspects may play a crucial role for the class of elderly cases comprising geriatric patients with impaired mobility as well as increased need of care and support by their relatives. In this respect, consideration of certification status is may of minor interest regarding selection of an appropriate hospital because older patient as well as their caregiving families might prefer a facility close to their home. These assumptions correspond to our finding that older breast cancer patients were more likely to be reported by non-certified facilities.

The herein presented results were solely based on quality proven data of the Cancer Registry of Rhineland-Palatinate. Inaccurate or incomplete reports were not considered.

In conclusion, our investigation showed that most breast and more than a quarter of prostate cancer patients were treated in DKG-certified centers. The region of residence seemed to affect the decision for a certain facility for all patients. Whereas age at diagnosis and tumor status played a role for breast and prostate cancer patients, respectively. These results provide first insight into factors stimulating treatment in a certain facility and represent a suitable basis for further studies in other federal states in Germany as well as other countries with comparable certification programs.

\section{Declarations}

\section{Funding}

Not applicable

\section{Conflict of interest}

The authors report no conflicts of interest.

\section{Ethics approval}

Not applicable

\section{Consent to participate}


Consent for participate was obtained from all authors.

\section{Consent for publication}

Consent for publication was obtained from all authors

\section{Data Availability}

The datasets generated and analyzed during the current study are available from the corresponding author on reasonable request.

\section{Author's contribution}

RS: This author contributed to the concept and design of the study and the interpretation of the results and writing of the paper. She approved the final version for publication and agrees to be accountable for all aspects of the work.

$\mathrm{RH}$ : This author contributed to the concept and design of the study and the interpretation of the results and statistical analysis. He approved the final version for publication, and agrees to be accountable for all aspects of the work. CJ: This author contributed to the concept and design of the study and the interpretation of the results and writing of the paper. She approved the final version for publication and agrees to be accountable for all aspects of the work.

\section{Code Availability}

Not applicable

\section{References}

1. Ferlay J et al. Cancer Today; 2020 [cited 02.2021]. Available from: URL: https://gco.iarc.fr/today.

2. OncoMap. Liste der zertifizierten Krebszentren: Deutsche Krebsgesellschaft e.V.; 2020. Available from: URL: https://www.oncomap.de/centers?selectedCounty=Deutschland\&selectedState=Rheinland-Pfalz.

3. Deutsche Krebsgesellschaft e.V. Das Zertifizierungsprogramm der Deutschen Krebsgesellschaft | DKG; 2021 [cited 2021 Jun 15 ]. Available from: URL: https://www.krebsgesellschaft.de/deutsche-krebsgesellschaft/zertifizierung.html.

4. Kowalski et al. Shifting cancer care towards Multidisciplinarity: the cancer center certification program of the German cancer society. BMC Cancer 2017.

5. Onkozert. Phasen der Zertifizierung; 2020 [cited 2020 Apr 30]. Available from: URL: https://www.onkozert.de/informationen/phasen/.

6. Lux MP, Hildebrandt T, Bani MR, Schrauder MG, Löhberg CR, Fasching PA et al. Gesundheitsökonomische Aspekte und finanzielle Probleme in den zertifizierten Strukturen des Fachgebietes. Gynäkologe 2011; 44(10):816-26.

7. Krebsregister Rheinland-Pfalz gGmbH. Was wir tun; 2021 [cited 2021 Jun 15]. Available from: URL: https://www.krebsregister-rlp.de/ueberuns/was-wir-tun/.

8. World Health Oraniation. Cancer; 2021 [cited 2021 Aug 26]. Available from: URL: https://www.who.int/news-room/fact-sheets/detail/cancer.

9. Deutsche Krebsgesellschaft e.V., Deutsche Krebshilfe, Arbeitsgemeinschaft der Wissenschaftlichen Medizinischen Fachgesellschaften e.V. Interdisziplinäre S3-Leitlinie für die Früherkennung, Diagnostik, Therapie und Nachsorge des Mammakarzinoms: Langversion 4.3 - Februar 2020 AWMF-Registernummer: 032-045OL. Leitlinienprogramm Onkologie 2020 [cited 2020 Apr 30]. Available from: URL: https://www.leitlinienprogrammonkologie.de/fileadmin/user_upload/Downloads/Leitlinien/Mammakarzinom_4_0/Version_4.3/LL_Mammakarzinom_Langversion_4.3.pdf.

10. Deutsche Krebsgesellschaft e.V., Deutsche Krebshilfe, Arbeitsgemeinschaft der Wissenschaftlichen Medizinischen Fachgesellschaften e.V. Interdisziplinäre Leitlinie der Qualität S3 zur Früherkennung, Diagnose und Therapie der verschiedenen Stadien des Prostatakarzinoms: Version 5.1 - Mai 2019 AWMF-Registernummer: 043/022OL. Leitlinienprogramm Onkologie 2019 [cited 2020 Apr 30]. Available from: URL: https://www.leitlinienprogrammonkologie.de/fileadmin/user_upload/Downloads/Leitlinien/Prostata_5_0/LL_Prostatakarzinom_Langversion_5.1.pdf.

11. Deutscher Ärzteverlag GmbH, Redaktion Deutsches Ärzteblatt. Erreichbarkeit von Ärzten: Stadt-Land-Gefälle besteht weiter; 2016 [cited 2021 Jun 15]. Available from: URL: https://www.aerzteblatt.de/nachrichten/71556/Erreichbarkeit-von-Aerzten-Stadt-Land-Gefaelle-besteht-weiter.

12. Ambroggi M, Biasini C, Del Giovane C, Fornari F, Cavanna L. Distance as a Barrier to Cancer Diagnosis and Treatment: Review of the Literature. Oncologist 2015; 20(12):1378-85.

13. Hornova J, Bortlicek Z, Majkova P, Abrahamova J, Kordikova D, Donatova Z et al. Locally advanced breast cancer in elderly patients. Biomed Pap Med Fac Univ Palacky Olomouc Czech Repub 2017; 161(2):217-22. 
14. Arbeitsgemeinschaft Deutscher Tumorzentren e.V., Gesellschaft der epidemiologischen Krebsregister in Deutschland e.V. Einheitlicher Onkologischer Basisdatensatz; 2014.

15. Krebsregister Rheinland-Pfalz gGmbH. Bericht des Krebsregisters Rheinland-Pfalz 2020/21; 2020.

16. Statistisches Landesamt Rheinland-Pfalz. Basisdaten regional; 2021 [cited 2021 Jun 15]. Available from: URL: https://www.statistik.rlp.de/de/gesellschaft-staat/bevoelkerung-und-gebiet/basisdaten-regional.

17. Wittekind C. TNM Klassifikation maligner Tumoren. 8th ed. Weinheim: Wiley-VCH; 2017.

18. Integrated Development for R: RStudio. Boston, MA, USA; 2020. Available from: URL: http://www.rstudio.com/.

19. IBM SPSS Statistics for Windows. Version 27.0. Armonk, NY; 2020. 